\title{
Implications of supermarket access, neighbourhood walkability and poverty rates for diabetes risk in an employee population
}

\author{
Cynthia J Herrick ${ }^{1, *}$, Byron W Yount ${ }^{2}$ and Amy A Eyler ${ }^{3}$
}

'Division of Endocrinology, Metabolism, and Lipid Research, Department of Medicine, Washington University School of Medicine, Campus Box 8127, 660 S. Euclid Avenue, St. Louis, MO 63110, USA: ${ }^{2}$ Mercy Research and Mercy Center for Data Innovation, St. Louis, MO, USA: ${ }^{3}$ Prevention Research Center, George Warren Brown School of Social Work, Washington University, St. Lovis, MO, USA

Submitted 9 April 2015: Final revision received 6 October 2015: Accepted 26 0ctober 2015: First published online 7 December 2015

\begin{abstract}
Objective: Diabetes is a growing public health problem, and the environment in which people live and work may affect diabetes risk. The goal of the present study was to examine the association between multiple aspects of environment and diabetes risk in an employee population.

Design: This was a retrospective cross-sectional analysis. Home environment variables were derived using employees' zip code. Descriptive statistics were run on all individual- and zip-code-level variables, stratified by diabetes risk and worksite. A multivariable logistic regression analysis was then conducted to determine the strongest associations with diabetes risk.

Setting: Data were collected from employee health fairs in a Midwestern health system, 2009-2012.

Subjects: The data set contains 25227 unique individuals across four years of data. From this group, using an individual's first entry into the database, 15522 individuals had complete data for analysis.

Results: The prevalence of high diabetes risk in this population was $2 \cdot 3 \%$. There was significant variability in individual- and zip-code-level variables across worksites. From the multivariable analysis, living in a zip code with higher percentage of poverty and higher walk score was positively associated with high diabetes risk, while living in a zip code with higher supermarket density was associated with a reduction in high diabetes risk.

Conclusions: Our study underscores the important relationship between poverty, home neighbourhood environment and diabetes risk, even in a relatively healthy employed population, and suggests a role for the employer in promoting health.
\end{abstract}

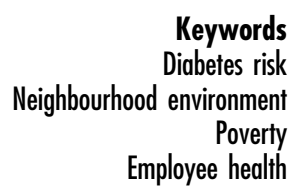

Keywords

Poverty

Employee health
Diabetes affects more than $9 \%$ of the US adult population, with a prevalence that increases with age and varies by socio-economic status, race and ethnicity, with minority and low-income populations being disproportionately affected $^{(1)}$. Another $37 \%$ of the US adult population over 20 years of age is estimated to have pre-diabetes ${ }^{(2)}$. Diabetes has vast public health implications. In 2010, diabetes was the seventh leading cause of death and is a risk factor for heart disease, which continues to be the leading cause of death ${ }^{(3)}$. The vast majority of diabetes cases in the USA are type 2 diabetes, related to obesity and insulin resistance ${ }^{(4)}$. In addition to increased mortality, people with diabetes incur medical expenses that are more than twice as high as people without diabetes. Indirect costs of the disease are also high, with an estimated \$US 50 billion attributed to workdays lost, reduced productivity at work, reduced productivity for those out of work and reduced labour force participation in $2012^{(5)}$.

Prevention and control of type 2 diabetes relies on healthy lifestyle modification. Modifying diet and exercise to achieve modest weight loss, in the range of $5-10 \%$ of body weight, has been shown to be more effective in diabetes prevention than medication ${ }^{(6)}$. Environmental strategies are one way to target population changes in these healthy lifestyle behaviours $^{(7)}$. Improving access to places to purchase healthy foods, removing barriers to healthy food choice and increasing opportunities for physical activity are nationally recommended strategies for improving population health ${ }^{(8,9)}$. Two recent systematic reviews demonstrate associations between the food and built environments in residential settings and obesity and physical activity, although the mechanism for such associations is not always clear ${ }^{(10,11)}$. 
Multiple constructs for measuring the food and built environments have been proposed to assist in developing a consistent definition for cross-comparison ${ }^{(12,13)}$. For the food environment, community-level measures use geo-localized data to determine density or proximity of food stores classified as 'healthy' (grocery stores, produce vendors) or 'unhealthy' (convenience stores, fast-food chains) ${ }^{(14-16)}$. Consumer-level measures include questionnaires, sales, nutrient or menu analyses, and validated tools, such as the Nutrition Environment Measures Survey (NEMS), that account for availability, price and quality of certain food categories ${ }^{(15,17-19)}$. The relationship between the food environment, diet and obesity is complex. Perceived food availability consistently associates with fruit/vegetable consumption, while store audits of product availability and geo-localized measures of store density sometimes correlate with healthy intake ${ }^{(20)}$. Overall, greater access to supermarkets and lower access to fast-food and convenience stores is associated with lower BMI, although this is not always mediated by a healthier diet, at least as measured by fruit/vegetable intake, and may not always be true in rural areas $^{(11,21-24)}$.

Similar to measurement complexities with the food environment, the built environment as it relates to physical activity has multiple components. Built environment may be measured according to individual perceptions, community audits, or using geographic information systems. Components of the built environment that affect physical activity include availability of sidewalks and bike lanes for active transit, land-use mix and proximity to stores and restaurants in residential neighbourhoods, crime rates and public safety, and access to recreation facilities and green space ${ }^{(25)}$.

Finally, socio-economic status and race are important determinants of access to healthy environments and ultimately health outcomes. According to statistics from the 2012 National Health Interview Survey, 13.7\% of patients with incomes below the federal poverty level (FPL; low-income) had diabetes, compared with $7 \cdot 1 \%$ of individuals with incomes $200 \%$ of the FPL or above (not low-income). Low-income individuals are half as likely as individuals who are not low-income to report meeting physical activity guidelines. Finally $32.1 \%$ of low-income individuals are obese while only $26.4 \%$ of individuals who are not low-income are obese ${ }^{(1)}$. An analysis conducted in 2006 in St. Louis, MO, USA, the city from which much our study population was derived, using a combination of food audits and geographic information system techniques, found that lower-income census tracts and predominantly African American census tracts were less likely to have access to supermarkets providing options that meet the US Department of Agriculture's dietary guidelines than predominantly white, high-income census tracts $^{(26)}$.

Very few studies have examined the specific association of home neighbourhood environment with diabetes risk.
Among participants in the African American Health Study (also in St. Louis, MO, USA), poor housing conditions were associated with self-reported diabetes, even after adjusting for possible mediators ${ }^{(27)}$. Further, a randomized trial found that providing housing vouchers to move from a high-poverty to a low-poverty census tract was associated with lower prevalences of diabetes and extreme obesity over 10-15 years of follow-up ${ }^{(28)}$. In a pooled analysis of cross-sectional studies in a German population, high unemployment rates were associated with increased odds of self-reported diabetes ${ }^{(29)}$. Finally, a recent longitudinal analysis of the Multi-Ethnic Study of Atherosclerosis cohort found a lower risk for developing type 2 diabetes with more exposure to neighbourhood healthy food resources and physical activity environments ${ }^{(30)}$.

To our knowledge, no studies have explicitly examined associations between the home neighbourhood environment and diabetes risk in a healthy, employed population. Our current study seeks to address this gap in the literature by exploring the association between multiple aspects of the home neighbourhood environment and diabetes risk among a large sample of employees within a health-care system.

\section{Methods}

\section{Sample}

Our sample consists of employees attending on-site health fairs in a single Midwestern health system with ten hospitals and five administrative sites. Data were collected at all sites at annual health fairs held during 2009-2012. The data set contains 25227 unique individuals across four years of data. From this group, using an individual's first entry into the database for cross-sectional evaluation, 15522 individuals had complete data on all independent predictors for inclusion in the multivariable analysis. These 15522 individuals comprise the study population, which was generally representative of the full data set, although women comprised a higher percentage of the high risk for diabetes group in the study population.

At the health fair, individuals reported height, weight, birth date, gender, zip code and usual workplace. Capillary blood glucose (designated as fasting or nonfasting), total cholesterol and HDL cholesterol (HDL-C) were measured using the Cholestech LDX system (Alere Home Monitoring, Livermore, CA, USA). Blood pressure was measured using a manual sphygmomanometer (Welch Allyn, Skaneateles Falls, NY, USA).

\section{Variables}

\section{Individual}

For glucose and cholesterol, reasonable ranges were defined according to the limits of detection on the Cholestech LDX system (glucose, $2.76-27.55 \mathrm{mmol} / 1$ (50-500 mg/dl); total cholesterol, $2.59-12.93 \mathrm{mmol} / 1$ 
(100-500 mg/dl); HDL-C, 0.39-2.59 mmol/1 (15-100 mg/dl)). For systolic blood pressure and BMI, reasonable ranges were defined according to what could reasonably be expected for an ambulatory patient (systolic blood pressure, $80-250 \mathrm{mmHg}$; BMI, $13-150 \mathrm{~kg} / \mathrm{m}^{2}$ ). Individuals with recorded ages from 16 to 90 years were included. Values outside these ranges for each respective variable were coded to missing.

\section{Zip code/environmental}

Zip code was used as a proxy for home neighbourhood. As income and race were not available at the individual level in this data set, we linked our data to the American Community Survey (2008-2012) by zip code to create a variable reflecting the percentage of the population in the zip code that was below the FPL and the percentage of the zip code that was African American ${ }^{(31,32)}$. To reflect the food environment within an employee's zip code, the density per square mile $\left(2.59 \mathrm{~km}^{2}\right)$ for supermarkets was calculated using 2011 Zip Code Business Patterns by Employee Size Class and 2010 Census Zip Code land area $^{(33,34)}$. A supermarket was defined as a grocery store with fifty or more employees as per prior research and represented a place where individuals were likely to have access to healthy foods and year-round produce ${ }^{(35)}$. While density of farmers' markets, convenience stores or fast-food restaurants could also reflect the food environment, supermarket density has been correlated with two different global dietary measures ${ }^{(36)}$. Also, of the available zip-code-level food environment variables that could be derived using the Zip Code Business Patterns data, supermarket density was available for the largest number of individuals in the data set. The Walk Score ${ }^{\circledR}$ for the employee's zip code was used to represent the built environment in the home neighbourhood. The Walk Score is an open-source measure of the built environment available at the zip code level. A population-weighted score from 0 to 100 (with higher scores corresponding to more walker-friendly environments) is calculated for the zip code, using distance to amenities, block length and intersection density. It has been demonstrated to be a reasonable measure of neighbourhood walkability ${ }^{(37)}$.

\section{Analysis}

All analyses were conducted using the statistical software package IBM SPSS Statistics version 21. For the purpose of our multivariable regression analysis, the dependent variable was high risk for diabetes. This was calculated according to the American Diabetes Association's definition of diabetes: fasting glucose $>6.94 \mathrm{mmol} / \mathrm{l}(125 \mathrm{mg} / \mathrm{dl})$ or random glucose $\geq 11.11 \mathrm{mmol} / \mathrm{l} \quad(200 \mathrm{mg} / \mathrm{dl})$. We have designated this category as high risk for diabetes, rather than diagnosis of diabetes, as we have only single measurements of capillary blood glucose and the American Diabetes Association requires a repeated measurement for confirmation. Descriptive statistics were evaluated and bivariate analyses conducted for each variable, stratified by diabetes risk and worksite. Variables were evaluated for normality using the KolmogorovSmirnov and Shapiro-Wilk $W$ tests and visual inspection of histograms. None of our continuous predictor variables were normally distributed, thus $P$ values for comparison between diabetes risk groups were based upon comparison of mean ranks using the Mann-Whitney $U$ test. The $\chi^{2}$ statistic was used to evaluate differences between groups on categorical variables. Differences among continuous variables by worksite were evaluated using the Kruskal-Wallis statistic. Age, gender, BMI, non-HDL-C (total cholesterol minus HDL-C) and systolic blood pressure were included in the multivariable model as independent predictors. Zip-code-level variables (percentage of the zip code below the FPL, percentage of the zip code African American, Walk Score, supermarket density) and relevant interaction terms were then added to this model individually to determine if their inclusion added to the predictive value of the model for high risk of diabetes. Standardized variables were used in the multivariable model such that the adjusted odds ratio represents the anticipated change in high diabetes risk with a change of $1 \mathrm{SD}$ in the independent predictor variable. Multicollinearity diagnostics were run on variables in the final model to ensure that no two variables in the model were collinear. The zip-code-level race variable was excluded because of collinearity with the zip-code-level income variable (variance inflation factor $\sim 2.9$ and tolerance $\sim 0.35$ ). A multilevel analysis was not undertaken because workplace-level environment variables (i.e. objective assessments of the food and built environments at the worksite) were not available. Furthermore, as all worksites in this sample were part of the same health system, variability in the workplace food and built environments was anticipated to be low.

\section{Results}

Descriptive statistics for the final population of 15522 participants are provided in Tables 1 and 2. Table 1 contains data stratified by diabetes risk and Table 2 contains data stratified by workplace. Employees with high risk for diabetes were significantly older $(49.8 v$. 40.8 years; $P<0.001)$, with higher mean BMI $\left(33.7 v .28 \cdot 1 \mathrm{~kg} / \mathrm{m}^{2}\right.$; $P<0.001)$, systolic blood pressure (130.7 v. $118.3 \mathrm{mmHg}$; $P<0.001)$ and non-HDL-C $(3.85 v .3 .37 \mathrm{mmol} / 1$ (148.6 $v$. $130.2 \mathrm{mg} / \mathrm{dl}$ ); $P<0.001)$ than those without high risk for diabetes in bivariate comparisons. Employees with high risk for diabetes also lived in zip codes with a higher percentage of African Americans, a higher percentage of the population below the FPL and higher Walk Score. In fact, $43.2 \%$ of those with high risk for diabetes lived in a low-income zip code, defined as a zip code with $\geq 20 \%$ of 
Table 1 Characteristics of the employee population attending Midwestern health fairs, 2009-2012, stratified by diabetes risk

\begin{tabular}{|c|c|c|c|c|c|c|c|c|}
\hline & \multicolumn{8}{|c|}{ Individual-level data } \\
\hline & \multicolumn{2}{|c|}{ Age (years) $†$} & \multicolumn{2}{|c|}{ BMI $\left(\mathrm{kg} / \mathrm{m}^{2}\right) \dagger$} & \multicolumn{2}{|c|}{ SBP $(\mathrm{mmHg}) \dagger$} & \multicolumn{2}{|c|}{ Non-HDL-C $(\mathrm{mmol} / \mathrm{l}) \dagger$} \\
\hline & Mean & SD & Mean & SD & Mean & SD & Mean & SD \\
\hline \multirow[t]{4}{*}{$\begin{array}{l}\text { High risk for diabetes ( } n 361) \\
\text { Not high risk for diabetes }(n 15161) \\
\text { Total population ( } n 15522)\end{array}$} & $\begin{array}{l}49 \cdot 8^{\star \star \star} \\
40 \cdot 8 \\
41 \cdot 0\end{array}$ & $\begin{array}{l}10 \cdot 3 \\
12 \cdot 6 \\
12 \cdot 6\end{array}$ & $\begin{array}{l}33 \cdot 7^{\star \star \star} \\
28 \cdot 1 \\
28 \cdot 3\end{array}$ & $\begin{array}{l}7 \cdot 8 \\
6 \cdot 8 \\
6 \cdot 9\end{array}$ & $\begin{array}{l}130 \cdot 7^{\star \star \star} \\
118 \cdot 3 \\
118 \cdot 6\end{array}$ & $\begin{array}{l}18 \cdot 3 \\
15 \cdot 7 \\
15 \cdot 9\end{array}$ & $\begin{array}{l}3 \cdot 85^{\star \star \star} \\
3 \cdot 37 \\
3 \cdot 38\end{array}$ & $\begin{array}{l}1.24 \\
1.01 \\
1.02\end{array}$ \\
\hline & \multicolumn{8}{|c|}{ Zip-code-level data } \\
\hline & \multicolumn{2}{|c|}{$\begin{array}{c}\text { African American } \\
(\%) \dagger\end{array}$} & \multicolumn{2}{|c|}{$\begin{array}{l}\text { Population below } \\
\text { FPL }(\%) \dagger\end{array}$} & \multicolumn{2}{|c|}{ Walk Score ${ }^{\circledR} \dagger$} & \multicolumn{2}{|c|}{$\begin{array}{l}\text { Supermarket density (stores per } \\
\left.\text { square mile }\left(2.59 \mathrm{~km}^{2}\right)\right) \dagger\end{array}$} \\
\hline & Mean & SD & Mean & SD & Mean & SD & Mean & SD \\
\hline $\begin{array}{l}\text { High risk for diabetes }(n 361) \\
\text { Not high risk for diabetes }(n 15161) \\
\text { Total population ( } n 15522)\end{array}$ & $\begin{array}{l}36 \cdot 3^{\star \star \star} \\
23 \cdot 4 \\
23 \cdot 7\end{array}$ & $\begin{array}{l}34 \cdot 0 \\
29 \cdot 0 \\
29 \cdot 4\end{array}$ & $\begin{array}{l}18 \cdot 4^{\star \star \star} \\
14 \cdot 2 \\
14 \cdot 3\end{array}$ & $\begin{array}{l}10 \cdot 6 \\
10 \cdot 1 \\
10 \cdot 1\end{array}$ & $\begin{array}{l}39 \cdot 4^{*} \\
36 \cdot 6 \\
36 \cdot 6\end{array}$ & $\begin{array}{l}22 \cdot 7 \\
24 \cdot 6 \\
24 \cdot 6\end{array}$ & $\begin{array}{l}0.16 \\
0.19 \\
0.19\end{array}$ & $\begin{array}{l}0.20 \\
0.28 \\
0.27\end{array}$ \\
\hline \multirow{2}{*}{ Total population ( $n 15522$ ) } & \multicolumn{8}{|c|}{ Population with certain characteristics } \\
\hline & \multicolumn{2}{|c|}{ Male (\%)‡ } & \multicolumn{2}{|c|}{ Female $(\%) \ddagger$} & \multicolumn{2}{|c|}{$\begin{array}{c}\text { Obese }\left(\mathrm{BMl} \geq 30 \mathrm{~kg} / \mathrm{m}^{2}\right) \\
(\%) \ddagger\end{array}$} & \multicolumn{2}{|c|}{$\begin{array}{l}\text { Living in low-income } \\
\text { zip code }(\%) \ddagger, \S\end{array}$} \\
\hline $\begin{array}{l}\text { High risk for diabetes }(n 361) \\
\text { Not high risk for diabetes }(n 15161) \\
\text { Total population }(n 15522)\end{array}$ & \multicolumn{2}{|c|}{$\begin{array}{l}24.4 \\
20.5\end{array}$} & \multicolumn{2}{|c|}{$\begin{array}{l}79.5 \\
79.4\end{array}$} & & & & \\
\hline
\end{tabular}

SBP, systolic blood pressure; Non-HDL-C, non-HDL cholesterol; FPL, federal poverty level.

Mean values or percentages were significantly different between high risk and not high risk groups: ${ }^{\star} P<0.05,{ }^{* \star *} P<0.001$.

tComparison between high risk and not high risk groups (based on Mann-Whitney $U$ test).

$\neq$ Comparison between high risk and not high risk groups (based on $x^{2}$ statistic).

$\S$ Low-income zip code $=$ zip code where $\geq 20 \%$ of the population is living below the FPL.

the population living below the FPL, whereas only $26 \cdot 2 \%$ of those without high risk for diabetes lived in a lowincome zip code. There were no significant differences between diabetes risk groups according to gender in the study population.

Fifteen worksites were represented in this sample and there was significant variability among worksites on many of these variables. While significant differences were seen among categories on all variables using the Kruskal-Wallis omnibus comparison, differences among worksites were most pronounced on zip-code-level variables. For example, the mean percentage of African American population in an employee's zip code ranged from 0.3 to $30.7 \%$. Likewise, the mean percentage of the population below the FPL in an employee's zip code ranged from $6 \cdot 1$ to $17.3 \%$ across worksites. The percentage of a worksite's employee population living in a low-income zip code ranged from 1.9 to $36.2 \%$. Mean Walk Score and supermarket density also ranged across worksites (mean Walk Score, $2 \cdot 3$ to $42 \cdot 5$; mean supermarket density, $0 \cdot 002$ to $0 \cdot 23$ stores per square mile $\left.\left(2.59 \mathrm{~km}^{2}\right)\right)$. Worksites were predominantly female, consistent with the health-care industry, but those sites that housed administrative and corporate staff had a higher percentage of male employees $^{(38)}$.

In our multivariable logistic regression analysis, shown in Table 3, after adjusting for age, BMI, gender, non-HDL-C and systolic blood pressure, living in a zip code with a higher percentage of the population below the FPL was independently associated with high risk for diabetes. When included in the model individually, neither Walk Score nor supermarket density had a significant association with diabetes risk when adjusting for other variables; however, when included in the model together, a higher Walk Score was positively associated with a high risk for diabetes while a higher supermarket density was associated with a reduction in high risk for diabetes.

\section{Discussion}

Socio-economic factors are increasingly recognized to be important determinants of health. In particular, in developed countries, rates of obesity are inversely associated with socio-economic status, particularly in women ${ }^{(39)}$. Obesity increases risks for a number of chronic health conditions including diabetes ${ }^{(40)}$. Our analysis underscores this relationship between income and diabetes risk and suggests a role for the home neighbourhood environment.

Our variables reflecting the home neighbourhood food and built environments (zip code supermarket density and Walk Score, respectively) demonstrated small but statistically significant associations with high risk for diabetes 
Table 2 Characteristics of the employee population attending Midwestern health fairs, 2009-2012, stratified by worksite

\begin{tabular}{|c|c|c|c|c|c|c|c|c|}
\hline & \multicolumn{8}{|c|}{ Individual-level data } \\
\hline & \multicolumn{2}{|c|}{ Age (years) $†$} & \multicolumn{2}{|c|}{ BMI $\left(\mathrm{kg} / \mathrm{m}^{2}\right) \dagger$} & \multicolumn{2}{|c|}{ SBP $(\mathrm{mmHg}) \dagger$} & \multicolumn{2}{|c|}{ Non-HDL-C $(\mathrm{mmol} / \mathrm{l}) \dagger$} \\
\hline & Mean & SD & Mean & SD & Mean & SD & Mean & SD \\
\hline Site 1 ( $n 370)$ & 44.6 & 11.9 & $28 \cdot 3$ & $6 \cdot 0$ & $116 \cdot 4$ & $15 \cdot 0$ & 3.42 & 0.99 \\
\hline Site 2 (n 409) & 38.4 & 11.6 & 29.7 & 8.9 & $116 \cdot 9$ & $14 \cdot 0$ & 3.29 & 1.04 \\
\hline Site 3 ( $n$ 855) & 44.0 & 11.0 & 28.4 & $6 \cdot 6$ & $120 \cdot 7$ & $15 \cdot 3$ & 3.57 & 1.02 \\
\hline Site 4 (n 404) & 38.7 & 11.7 & 28.3 & 6.5 & 115.5 & 14.9 & 3.27 & 1.02 \\
\hline Site 5 ( $n$ 6126) & $40 \cdot 4$ & $12 \cdot 6$ & $28 \cdot 3$ & $7 \cdot 0$ & $119 \cdot 3$ & $16 \cdot 2$ & 3.37 & 1.05 \\
\hline Site 6 ( $n$ 549) & 43.3 & $12 \cdot 3$ & $27 \cdot 7$ & $6 \cdot 1$ & 117.5 & $14 . \overline{7}$ & 3.43 & 0.99 \\
\hline Site 7 (n 359) & 44.4 & $12 \cdot 4$ & $27 \cdot 4$ & $6 \cdot 2$ & 118.0 & $15 \cdot 4$ & 3.37 & 0.98 \\
\hline Site 8 ( $n$ 1448) & 40.5 & 14.0 & 28.8 & $6 . \overline{7}$ & 118.7 & $15 \cdot 6$ & 3.39 & 0.98 \\
\hline Site $9(n 75)$ & $42 \cdot 8$ & $12 \cdot 1$ & 28.2 & 7.5 & $115 \cdot 8$ & $15 \cdot 0$ & 3.21 & 0.97 \\
\hline Site $10(n 353)$ & $46 \cdot 8$ & $10 \cdot 4$ & 29.7 & 7.5 & $120 \cdot 0$ & $16 \cdot 2$ & 3.48 & 1.00 \\
\hline Site $11(n 179)$ & 41.2 & 11.9 & 28.8 & 7.0 & $116 \cdot 1$ & $12 \cdot 8$ & 3.36 & 1.07 \\
\hline Site 12 ( $n$ 1801) & $42 \cdot 1$ & $12 \cdot 4$ & $28 \cdot 1$ & $6 \cdot 6$ & 118.9 & $16 \cdot 0$ & 3.44 & 0.99 \\
\hline Site $13(n 188)$ & $42 \cdot 9$ & 13.5 & $28 \cdot 7$ & $6 \cdot 1$ & 116.5 & $15 \cdot 3$ & 3.57 & 0.97 \\
\hline Site $14(n 155)$ & $42 \cdot 1$ & 11.0 & 28.3 & $6 \cdot 7$ & $115 \cdot 6$ & 14.5 & 3.49 & 0.89 \\
\hline Site 15 ( $n$ 2251) & $38 \cdot 8$ & $12 \cdot 3$ & $27 \cdot 6$ & $6 \cdot 8$ & $117 \cdot 8$ & $16 \cdot 2$ & $3 \cdot 27$ & 0.98 \\
\hline
\end{tabular}

\begin{tabular}{|c|c|c|c|c|c|c|c|c|}
\hline & \multicolumn{2}{|c|}{ African American (\%)† } & \multicolumn{2}{|c|}{ Population below FPL (\%)† } & \multicolumn{2}{|c|}{ Walk Score ${ }^{\circledR} \dagger$} & \multicolumn{2}{|c|}{$\begin{array}{l}\text { Supermarket density }(\text { stores } \\
\left.\text { per square mile }\left(2.59 \mathrm{~km}^{2}\right)\right)\end{array}$} \\
\hline & Mean & SD & Mean & SD & Mean & SD & Mean & SD \\
\hline Site 1 (n 370) & 8.2 & $12 \cdot 0$ & 13.4 & $4 \cdot 8$ & $17 \cdot 9$ & 23.4 & 0.04 & 0.06 \\
\hline Site 2 ( $n$ 409) & 26.0 & 30.0 & $15 \cdot 5$ & 9.8 & 37.0 & $24 \cdot 2$ & 0.18 & 0.25 \\
\hline Site $3(n 855)$ & $18 \cdot 1$ & 24.7 & 11.7 & $9 \cdot 0$ & $36 \cdot 7$ & 23.5 & 0.19 & 0.26 \\
\hline Site 4 ( $n$ 404) & $15 \cdot 8$ & $22 \cdot 3$ & $12 \cdot 0$ & $7 \cdot 6$ & $29 \cdot 2$ & 23.5 & 0.15 & 0.24 \\
\hline Site 5 ( $n 6126)$ & $30 \cdot 3$ & $32 \cdot 2$ & $16 \cdot 6$ & $11 \cdot 1$ & $42 \cdot 5$ & 23.5 & 0.22 & 0.31 \\
\hline Site 6 ( $n$ 549) & 6.9 & 11.8 & $6 \cdot 8$ & 5.4 & $25 \cdot 7$ & $25 \cdot 1$ & 0.09 & 0.10 \\
\hline Site 7 ( $n$ 359) & $17 \cdot 4$ & $25 \cdot 2$ & 10.8 & 8.6 & 31.6 & 22.9 & 0.16 & 0.18 \\
\hline Site 8 ( $n$ 1448) & 30.7 & 37.8 & $14 \cdot 8$ & 8.7 & $32 \cdot 9$ & 23.2 & 0.14 & 0.17 \\
\hline Site $9(n 75)$ & $19 \cdot 2$ & 24.0 & $12 \cdot 0$ & 8.2 & $35 \cdot 8$ & $22 \cdot 0$ & $0 \cdot 16$ & 0.19 \\
\hline Site $10(n 353)$ & 19.9 & $26 \cdot 7$ & $14 \cdot 1$ & $9 \cdot 0$ & 29.6 & 24.5 & 0.15 & 0.25 \\
\hline Site 11 ( $n$ 179) & 0.3 & 0.7 & $17 \cdot 3$ & 3.7 & 2.3 & $5 \cdot 1$ & 0.00 & 0.00 \\
\hline Site 12 ( $n$ 1801) & $16 \cdot 0$ & 24.9 & $10 \cdot 8$ & 8.4 & 32.9 & $22 \cdot 6$ & 0.17 & 0.21 \\
\hline Site $13(n 188)$ & 3.6 & 3.2 & $16 \cdot 5$ & 4.7 & $4 \cdot 1$ & 5.7 & 0.01 & 0.04 \\
\hline Site $14(n 155)$ & $6 \cdot 3$ & $9 . \overline{6}$ & $6 \cdot 1$ & 4.3 & $22 \cdot 4$ & 21.5 & 0.10 & 0.09 \\
\hline Site 15 ( $n$ 2251) & 23.7 & 28.5 & 14.6 & $10 \cdot 6$ & 41.3 & $24 \cdot 0$ & 0.23 & 0.33 \\
\hline
\end{tabular}

Workplace population with certain characteristics

\begin{tabular}{|c|c|c|c|c|c|}
\hline & $\begin{array}{l}\text { Male } \\
(\%) \ddagger\end{array}$ & $\begin{array}{c}\text { Female } \\
(\%) \ddagger\end{array}$ & $\begin{array}{c}\text { Obese }\left(\mathrm{BMI} \geq 30 \mathrm{~kg} / \mathrm{m}^{2}\right) \\
(\%) \ddagger\end{array}$ & $\begin{array}{l}\text { High risk for } \\
\text { diabetes }(\%) \S\end{array}$ & $\begin{array}{l}\text { Living in low-income } \\
\text { zip code }(\%) \ddagger, \|\end{array}$ \\
\hline Site 1 ( $n$ 370) & 13.5 & 86.5 & $32 \cdot 7$ & 1.6 & 1.9 \\
\hline Site 2 (n 409) & $19 \cdot 3$ & $80 \cdot 7$ & 37.9 & $3 \cdot 2$ & $30 \cdot 8$ \\
\hline Site $3(n 855)$ & 41.5 & 58.5 & 31.6 & 3.6 & $17 \cdot 7$ \\
\hline Site 4 (n 404) & $10 \cdot 6$ & $89 \cdot 4$ & $31 \cdot 7$ & $2 \cdot 5$ & $13 \cdot 6$ \\
\hline Site 5 ( $n$ 6126) & $23 \cdot 9$ & $76 \cdot 1$ & 33.0 & $2 \cdot 4$ & $36 \cdot 2$ \\
\hline Site 6 ( $(n 549)$ & $12 \cdot 0$ & 88.0 & 28.4 & $2 \cdot 0$ & 4.4 \\
\hline Site 7 ( $n$ 359) & $18 \cdot 1$ & 81.9 & $28 \cdot 7$ & $2 \cdot 8$ & $16 \cdot 2$ \\
\hline Site 8 ( $n$ 1448) & $19 \cdot 1$ & $80 \cdot 9$ & $37 \cdot 1$ & $2 \cdot 8$ & $25 \cdot 3$ \\
\hline Site $9(n 75)$ & $9 \cdot 3$ & $90 \cdot 7$ & $29 \cdot 3$ & 0.0 & $17 \cdot 3$ \\
\hline Site $10(n 353)$ & $14 \cdot 7$ & $85 \cdot 3$ & $42 \cdot 2$ & $2 \cdot 3$ & $25 \cdot 2$ \\
\hline Site 11 ( $n$ 179) & 14.5 & 85.5 & $36 \cdot 3$ & 1.7 & 27.4 \\
\hline Site 12 (n 1801) & $16 \cdot 3$ & $83 \cdot 7$ & $31 \cdot 3$ & 1.6 & $15 \cdot 3$ \\
\hline Site $13(n 188)$ & $16 \cdot 5$ & 83.5 & 34.6 & $2 \cdot 7$ & $28 \cdot 2$ \\
\hline Site 14 ( $n$ 155) & $16 \cdot 8$ & 83.2 & $32 \cdot 9$ & $3 \cdot 2$ & 3.9 \\
\hline Site 15 ( $n$ 2251) & $16 \cdot 1$ & 83.9 & 29.5 & 1.8 & 27.9 \\
\hline
\end{tabular}

SBP, systolic blood pressure; non-HDL-C, non-HDL Cholesterol; FPL, federal poverty level.

Highest and lowest values for each variable are indicated in bold.

†Statistical test for differences across worksites: Kruskal-Wallis omnibus comparison $P<0.001$.

‡Statistical test for differences across worksites (except high risk for diabetes): $X^{2}$ statistic $P<0.001$

$\S$ Unable to run $x^{2}$ statistic across sites for high risk for diabetes because number of cases is less than five at sites 9, 11 and 14 .

ILow-income zip code $=$ zip code where $\geq 20 \%$ of the population is living below the FPL. 
Table 3 Multivariable logistic regression: association between individual- and zip-code-level predictors and high diabetes risk among an employee population attending Midwestern health fairs, 2009-2012

\begin{tabular}{|c|c|c|}
\hline & \multicolumn{2}{|c|}{ High diabetes risk } \\
\hline & AOR & $95 \% \mathrm{Cl}$ \\
\hline \multicolumn{3}{|l|}{ Individual-level predictors } \\
\hline Age (years) $\dagger$ & 1.85 & $1 \cdot 64,2 \cdot 10$ \\
\hline Female genderł & 0.87 & $0.68,1.12$ \\
\hline $\mathrm{BMI}\left(\mathrm{kg} / \mathrm{m}^{2}\right) \dagger$ & 1.58 & $1.44,1.72$ \\
\hline $\mathrm{SBP}(\mathrm{mmHg}) \dagger$ & 1.29 & $1.17,1.42$ \\
\hline Non-HDL-C (mmol/l)† & 1.24 & $1.13,1.37$ \\
\hline \multicolumn{3}{|l|}{ Zip-code-level predictors } \\
\hline Population below FPL (\%)†,§ & 1.25 & $1.14,1.38$ \\
\hline Walk Score ${ }^{\circledR} \dagger$ & $1 \cdot 19$ & $1.04,1.37$ \\
\hline $\begin{array}{l}\text { Supermarket density } \\
\quad\left(\text { stores per square mile }\left(2.59 \mathrm{~km}^{2}\right)\right) \dagger\end{array}$ & $0 \cdot 84$ & $0.71,0.99$ \\
\hline \multicolumn{3}{|l|}{ Model summary } \\
\hline Nagelkerke $R^{2}$ & & 0.14 \\
\hline$C$ statistic & & 0.80 \\
\hline $95 \% \mathrm{Cl}$ & & $0.78,0.82$ \\
\hline \multicolumn{3}{|l|}{ Hosmer and Lemeshow test } \\
\hline$x^{2}$ & & 10.44 \\
\hline$\hat{d f}$ & & 8 \\
\hline$P$ value & & 0.24 \\
\hline
\end{tabular}

AOR, adjusted odds ratio; SBP, systolic blood pressure; Non-HDL-C non-HDL cholesterol; FPL, federal poverty level.

†All continuous explanatory variables in the model are standardized such that the odds ratio represents the effect of a $1 \mathrm{SD}$ change in the independent variable on the likelihood of high diabetes risk.

$\ddagger$ The gender variable compares females with the reference category (males).

$\S$ The zip-code-level race variable (percentage African American) was excluded from the multivariable analysis because of significant collinearity with percentage below the FPL.

when examined together. Although we hypothesized that living in a zip code with a higher Walk Score (representing a neighbourhood where it would be easier to be physically active) would be associated with a reduction in high diabetes risk, we found that there was actually a positive association between Walk Score and high diabetes risk. This is possibly because areas that have a higher Walk Score tend to be urban areas and there may be other factors associated with urban living and diabetes risk that were not captured in the analysis ${ }^{(41)}$. The Walk Score represents proximity to many amenities, and these may include restaurants, convenience stores and small grocery stores with unhealthy foods. Of note, an interaction term between Walk Score and supermarket density was not statistically significant and did not add to the explanatory power of the model. Also, simply living in a walkerfriendly neighbourhood does not automatically translate into increased physical activity that could lower obesity and diabetes risk. Living in a zip code with a higher supermarket density did appear to be associated with a reduction in high diabetes risk, similar to past research findings on the impact of community food access on obesity and cardiometabolic risk $^{(42,43)}$. While supermarkets contain many unhealthy foods, they are also likely to have a wider variety and selection of healthy foods than convenience stores or small grocery stores. Access to healthy foods is necessary for health, but the magnitude of this association may be affected by actual purchasing and consumption behaviours not measured in the present study.

\section{Limitations}

Our study has a number of limitations. First, our data represent a relatively healthy, employed, predominantly female population that was motivated to come to an employee health screening fair in exchange for eligibility for the lowest-premium health plan. Hence, results may not generalize to the population as a whole. The rate of high risk for diabetes in this population $(2.3 \%)$ is much lower than the US population rate of diabetes (>9\%), likely because our population represents a healthier group of individuals. Importantly, even in this healthy, employed population, living in areas with higher poverty is associated with high risk for diabetes. Further, we found that Walk Score and supermarket density affect diabetes risk in our model even in this healthy, employed population. It is possible that these effects would be even larger in the general population. Second, while our final study population is large, the population for which we have complete data comprises only about $60 \%$ of the people on whom any data were collected over this time frame. This may again affect the generalizability of our results. We also did not have individual-level data on race or ethnicity. This was an administrative decision made by the team conducting the health fairs to encourage participation, but it is an important variable in diabetes risk that we were unable to include in our analysis. We attempted to describe race within the communities in which our employees lived at the zip code level, but within our population this correlated strongly with poverty levels in those communities and both variables could not be used in the multivariable model together.

Our home environment variables were constructed at the zip code level because information in our de-identified database included employees' zip code rather than complete address. The clinical data collected for diabetes risk included only a random blood sugar, designated as fasting or non-fasting. Given that there are point-of-care devices that measure glycated $\mathrm{Hb}$ (HbA1C), an average of blood sugars over three months and definitions of diabetes according to $\mathrm{HbA} 1 \mathrm{C}$, measurement of this outcome in the future may give a richer assessment of diabetes in the population. Also, height and weight in the current data set are self-reported but could be reasonably easily measured. Finally, zip code has been used as a neighbourhood proxy in prior studies, but is limited in that it is not as specific as census tract and is a somewhat arbitrary designation based on mail routes. For example, there may be areas within zip codes that have better access to supermarkets, are safer and more walkable, and have higher-income households 
than other areas, and this variability and level of detail would not be reflected in the zip code average.

\section{Future directions and the role of the employer}

Since this was an employee population, our analysis raises important questions surrounding the role of the employer in addressing health. One important role highlighted by the present study is in screening for disease through health fairs. To maximize the impact of this activity for research and intervention, data should be collected in a comprehensive, systematic way. This includes collecting clinical data such as the measurement of HbA1C, height and weight as well as other relevant information such as job title, shift work, education level, income range, race, ethnicity, medical and family history, medications, health behaviour information on exercise, diet, smoking and alcohol use, and utilization of primary care. Employees who are identified as high risk should then be directed to primary care and workplace wellness programmes.

When we examined characteristics of employees at different worksites within the health-care system, we found a substantial degree of variability, particularly in the percentage of employees at each worksite living in low-income areas. Given that living in areas with higher poverty rates is positively associated with high risk for diabetes in our sample, our findings support a role for the employer as a resource for promoting health and addressing disparities. For low-income employees, employers can increase resources at work to reduce health risks.

Worksite wellness programmes addressing education, behaviour change, and the food or built environment are a priority in the Guide to Community Preventive Services and the Affordable Care Act, as a meta-analysis of randomized controlled trials demonstrated modest weight loss and BMI reduction with these programmes $(1.4 \mathrm{~kg}(3 \mathrm{lb})$ and $0 \cdot 5 \mathrm{~kg} / \mathrm{m}^{2}$ over 6-12 months) ${ }^{(44-46)}$. Emerging evidence suggests that employers may find return on investment for their wellness programmes in terms of reduced medical and absenteeism costs ${ }^{(47)}$. However, there is very little literature focusing on how workplace wellness programmes specifically address the needs of low-income workers ${ }^{(48,49)}$. Strategies to reach this population may be different and, in order to foster participation, programmes should use a participatory approach to engage employees early in designing and implementing programmes that best address the needs of these workers ${ }^{(50-52)}$.

Finally, the present study explored the relationship between diabetes risk and home environment in an employee population, but workplaces have the opportunity to create food and built environments that promote employee health as well. For example, in an environmental intervention within a healthcare workplace, nutritional labelling and altered product placement both reduced unhealthy item purchases, with intervention effects that were similar across race/ethnicity and job type and sustained over 2 years ${ }^{(53-55)}$. Short-term randomized environmental interventions have also resulted in significant increases in fruit, vegetable and fibre consumption and decreases in fat and sweets consumption among intervention employees ${ }^{(56-58)}$. Potential built environment supports include incentives for choosing to use stairwells instead of elevators, facilities that allow for active transportation to work, safe and walkable grounds, and flexible scheduling allowing employees time for exercise during the workday $^{(59)}$.

There is significant need for future research on home and work environments and related disease risk. In regard to assessing the food and built environments in both the home and workplace, more detailed information could be obtained on a subset of the population reflecting the actual availability and price of foods in their local supermarkets, as well as their food purchasing behaviours at home and at work. Likewise, actual activity could be monitored using accelerometer devices. There is also a need for more detailed metrics to measure food and built environments in the workplace. This would allow investigation of how workplace environments modify the effect of home environments on diabetes risk. Finally, future work in this area should define best practices and areas for improvement such that interventions to address diabetes risk and health in the home and work environments may be targeted and implemented effectively.

\section{Acknowledgements}

Acknowledgements: The authors thank June Fowler, Marci Allen, Ibby Woodsmall, Diane Zych and Kimberly Weir of BJC HealthCare for providing employee data for this study. Financial support: This work was supported by the National Institutes of Health (C.J.H., grant number 5T32DK007120-39) and the Washington University Center for Diabetes Translation Research (B.W.Y., grant number 5 P30 DK09295002). The funders had no role in the design, analysis or writing of this article. Conflicts of interest: None. Authorship: C.J.H formulated the research question, designed the study, conducted the analysis and drafted the manuscript. B.W.Y. cleaned and managed the data and assisted with the design of the analysis. A.A.E. guided the formulation of the research question, study design and analysis and edited the final manuscript. Ethics of human subject participation: This study was conducted according to the guidelines laid down in the Declaration of Helsinki and all procedures involving human subjects/patients were approved by the Washington University School of Medicine Institutional Review board. A waiver of consent was received given the retrospective nature of the analysis and de-identification of the data. 


\section{References}

1. Blackwell DL, Lucas JW \& Clarke TC (2014) Summary health statistics for US adults: National Health Interview Survey 2012. Vital Health Stat 10, issue 260, 1-161.

2. Centers for Disease Control and Prevention (2014) National Diabetes Statistics Report: Estimates of Diabetes and Its Burden in the United States, 2014. Atlanta, GA: US Department of Health and Human Services.

3. Centers for Disease Control and Prevention (2014) FastStats: Number of deaths for leading causes of death, 2010. http:// www.cdc.gov/nchs/fastats/leading-causes-of-death.htm (accessed August 2014).

4. Centers for Disease Control and Prevention (2014) National Diabetes Statistics Report: General Information. http://www.cdc.gov/diabetes/pdfs/data/2014-report-general information.pdf (accessed May 2015).

5. American Diabetes Association (2013) Economic costs of diabetes in the US in 2012. Diabetes Care 36, 1033-1046.

6. Knowler WC, Barrett-Connor E, Fowler SE et al.; Diabetes Prevention Program Research Group (2002) Reduction in the incidence of type 2 diabetes with lifestyle intervention or metformin. N Engl J Med 346, 393-403.

7. Casey AA, Elliot M, Glanz K et al. (2008) Impact of the food environment and physical activity environment on behaviors and weight status in rural US communities. Prev Med 47, 600-604

8. Centers for Disease Control and Prevention (2011) Strategies to Prevent Obesity and Other Chronic Diseases: The CDC Guide to Strategies to Increase the Consumption of Fruits and Vegetables. Atlanta, GA: US Department of Health and Human Services.

9. Centers for Disease Control and Prevention (2011) Strategies to Prevent Obesity and Other Chronic Diseases: The CDC Guide to Strategies to Increase Physical Activity in the Community. Atlanta, GA: US Department of Health and Human Services.

10. Ferdinand AO, Sen B, Rahurkar S et al. (2012) The relationship between built environments and physical activity: a systematic review. Am J Public Health 102, e7-e13.

11. Giskes K, vanLenthe F, Avendano-Pabon M et al. (2011) A systematic review of environmental factors and obesogenic dietary intakes among adults: are we getting closer to understanding obesogenic environments? Obes Rev $\mathbf{1 2}$ e95-e106.

12. Ball K, Timperio AF \& Crawford DA (2006) Understanding environmental influences on nutrition and physical activity behaviors: where should we look and what should we count? Int J Behav Nutr Phys Act 3, 33.

13. Saelens BE \& Glanz K (2009) Work group I: Measures of the food and physical activity environment: instruments. Am J Prev Med 36, 4 Suppl, S166-S170.

14. Matthews SA, Moudon AV \& Daniel M (2009) Work group II: Using Geographic Information Systems for enhancing research relevant to policy on diet, physical activity, and weight. Am J Prev Med 36, Suppl. 4, S171-S176.

15. McKinnon RA, Reedy J, Morrisette MA et al. (2009) Measures of the food environment: a compilation of the literature, 1990-2007. Am J Prev Med 36, Suppl. 4, S124-S133.

16. Charreire H, Casey R, Salze P et al. (2010) Measuring the food environment using geographical information systems: a methodological review. Public Health Nutr 13, $1773-1785$

17. Kelly B, Flood VM \& Yeatman H (2011) Measuring local food environments: an overview of available methods and measures. Health Place 17, 1284-1293.

18. Saelens BE, Glanz K, Sallis JF et al. (2007) Nutrition Environment Measures Study in Restaurants (NEMS-R): development and evaluation. Am J Prev Med 32, 273-281.
19. Glanz K, Sallis JF, Saelens BE et al. (2007) Nutrition Environment Measures Survey in Stores (NEMS-S): development and evaluation. Am J Prev Med 32, 282-289.

20. Caspi CE, Sorensen G, Subramanian SV et al. (2012) The local food environment and diet: a systematic review. Health Place 18, 1172-1187.

21. Rundle A, Neckerman KM, Freeman L et al. (2009) Neighborhood food environment and walkability predict obesity in New York City. Environ Health Perspect 117, 442-447.

22. Spence JC, Cutumisu N, Edwards J et al. (2009) Relation between local food environments and obesity among adults. BMC Public Health 9, 192.

23. Bodor JN, Rice JC, Farley TA et al. (2010) The association between obesity and urban food environments. J Urban Health 87, 771-781.

24. Ahern M, Brown C \& Dukas S (2011) A national study of the association between food environments and county-level health outcomes. J Rural Health 27, 367-379.

25. Brownson RC, Hoehner CM, Day K et al. (2009) Measuring the built environment for physical activity: state of the science. Am J Prev Med 36, Suppl. 4, S99-S123.

26. Baker EA, Schootman M, Barnidge E et al. (2006) The role of race and poverty in access to foods that enable individuals to adhere to dietary guidelines. Prev Chronic Dis 3, A76.

27. Schootman M, Andresen EM, Wolinsky FD et al. (2007) The effect of adverse housing and neighborhood conditions on the development of diabetes mellitus among middleaged African Americans. Am J Epidemiol 166, 379-387.

28. Ludwig J, Sanbonmatsu L, Gennetian L et al. (2011) Neighborhoods, obesity, and diabetes - a randomized social experiment. $N$ Engl J Med 365, 1509-1519.

29. Muller G, Kluttig A, Greiser KH et al. (2013) Regional and neighborhood disparities in the odds of type 2 diabetes: results from 5 population-based studies in Germany (DIAB-CORE consortium). Am J Epidemiol 178, 221-230.

30. Christine PJ, Auchincloss AH, Bertoni AG et al. (2015) Longitudinal associations between neighborhood physical and social environments and incident type 2 diabetes mellitus: the Multi-Ethnic Study of Atherosclerosis (MESA). JAMA Intern Med 175, 1311-1320.

31. US Census Bureau (2013) 2008-2012 American Community Survey 5-year Estimates - Selected Economic Characteristics - Income. http://factfinder2.census.gov/faces/table services/jsf/pages/productview.xhtml?pid=ACS_12_5YR_DP03\& prodType $=$ table (accessed February 2014).

32. US Census Bureau (2013) 2008-2012 American Community Survey 5-year Estimates - Demographic and Housing Estimates - Race/Ethnicity. http://factfinder2.census.gov/ faces/tableservices/jsf/pages/productview.xhtml?pid=ACS_12_ 5YR_DP05\&prodType=table (accessed February 2014).

33. US Census Bureau (2013) 2011 County Business Patterns: Zip Code Business Patterns by Employment Size Class (Missouri, Illinois; NAICS codes for food service, restaurants) CB1100CZ21. http://factfinder2.census.gov/faces/ tableservices/jsf/pages/productview.xhtml?pid=BP_2011_ 00CZ2\&prodType=table (accessed February 2014).

34. US Census Bureau (2012) 2010 Census Gazeteer Files - Zip Code Tabulation Areas. http://www.census.gov/geo/mapsdata/data/gazetteer2010.html (accessed February 2014).

35. Gibson DM (2011) The neighborhood food environment and adult weight status: estimates from longitudinal data. Am J Public Health 101, 71-78.

36. Moore LV, Diez-Roux AV, Nettleton JA et al. (2008) Associations of the local food environment with diet quality - a comparison of assessments based on surveys and geographic information systems: the multi-ethnic study of atherosclerosis. Am J Epidemiol 167, 917-924.

37. Hirsch JA, Moore KA, Evenson KR et al. (2013) Walk Score ${ }^{\circledR}$ and Transit Score ${ }^{\circledR}$ and walking in the multi-ethnic study of atherosclerosis. Am J Prev Med 45, 158-166. 
38. Bureau of Labor Statistics (2014) Labor Force Statistics from the Current Population Survey, 2013. http://www.bls.gov/ cps/cpsaat18.htm (accessed January 2015).

39. Ball K \& Crawford D (2005) Socioeconomic status and weight change in adults: a review. Soc Sci Med 60, 1987-2010.

40. Nguyen NT, Nguyen XT, Lane J et al. (2011) Relationship between obesity and diabetes in a US adult population: findings from the National Health and Nutrition Examination Survey, 1999-2006. Obes Surg 21, 351-355.

41. Saelens BF, Sallis JF \& Frank LD (2003) Environmental correlates of walking and cycling: findings from the transportation, urban design, and planning literatures. Ann Behav Med 25, 80-91.

42. Morland K, Diez-Roux AV \& Wing S (2006) Supermarkets, other food stores and obesity: the atherosclerosis risk in communities study. Am J Prev Med 30, 333-339.

43. Leal C \& Chaix B (2011) The influence of geographic life environments on cardiometabolic risk factors: a systematic review, a methodological assessment and a research agenda. Obes Rev 12, 217-230.

44. The Guide to Community Preventive Services (2007) Obesity prevention and control: worksite programs. http://www.thecommunityguide.org/obesity/workprograms. html (accessed September 2013).

45. Anderson LM, Quinn TA, Glanz K et al. (2009) The effectiveness of worksite nutrition and physical activity interventions for controlling employee overweight and obesity: a systematic review. Am J Prev Med 37, 340-357.

46. Madison K, Schmidt H \& Volpp KG (2013) Smoking, obesity, health insurance, and health incentives in the Affordable Care Act. JAMA 310, 143-144.

47. Baicker K, Cutler D \& Song Z (2010) Workplace wellness programs can generate savings. Health Aff (Millwood) 29, 304-311.

48. Rongen A, Robroek SJW, vanLenthe FJ et al. (2013) Workplace health promotion: a meta-analysis of effectiveness. Am J Prev Med 44, 406-415.
49. Heinen L \& Darling H (2009) Addressing obesity in the workplace: the role of employers. Milbank $Q$ 87, 101-122.

50. Punnett L, Warren N, Henning R et al.; CPH-NEW Research Team (2013) Participatory ergonomics as a model for integrated programs to prevent chronic disease. J Occup Environ Med 55, 12 Suppl, S19-S24.

51. Henning $\mathrm{R}$, Warren $\mathrm{N}$, Robertson $\mathrm{M}$ et al.; CHP-NEW Research Team (2009) Workplace health protection and promotion through participatory ergonomics: an integrated approach. Public Health Rep 124, Suppl. 1, 26-35.

52. Ferraro L, Faghri PD, Henning R et al.; CPH-NEW Research Team (2013) Workplace-based participatory approach to weight loss for correctional employees. J Occup Environ Med 55, 147-155.

53. Levy DE, Riis J, Sonnenberg LM et al. (2012) Food choices of minority and low-income employees: a cafeteria intervention. Am J Prev Med 43, 240-248.

54. Thorndike AN, Sonnenberg LM, Riis J et al. (2012) A 2-phase labeling and choice architecture intervention to improve healthy food and beverage choices. Am J Public Health 102, 527-533.

55. Thorndike AN, Riis J, Sonnenberg LM et al. (2014) Trafficlight labels and choice architecture: promoting healthy food choices. Am J Prev Med 46, 143-149.

56. Bandoni DH, Sarno F \& Jaime PC (2011) Impact of an intervention on the availability and consumption of fruits and vegetables in the workplace. Public Health Nutr 14, 975-981.

57. Lassen AD, Thorsen AV, Sommer HM et al. (2011) Improving the diet of employees at blue-collar worksites: results from the 'Food at Work' intervention study. Public Health Nutr 14, 965-974.

58. Beresford SAA, Thompson B, Feng Z et al. (2001) Seattle 5 a day worksite program to increase fruit and vegetable consumption. Prev Med 32, 230-238.

59. Chau J (2009) Evidence Module: Workplace Physical Activity and Nutrition Interventions. Sydney, NSW: University of Sydney, Physical Activity Nutrition and Obesity Research Group; available at http://hdl.handle.net/2123/9073 